\title{
Encapsulation of Red Cabbage (Brassica oleracea L. var. capitata L. f. rubra) Anthocyanins by Spray Drying using Different Encapsulating Agents
}

\author{
Anahi Bernstein and Caciano Pelayo Zapata Noreña* \\ Departamento de Tecnologia dos Alimentos; Instituto de Ciência e Tecnologia dos Alimentos; Universidade \\ Federal do Rio Grande do Sul;Porto Alegre - RS - Brasil
}

\begin{abstract}
This study aimed to evaluate the influence of the drying air temperature $\left(140\right.$ and $\left.160^{\circ} \mathrm{C}\right)$ and the concentration of encapsulating agents gum Arabic and polydextrose (10 and 15\%) on the physicochemical characteristics of the red cabbage extract obtained through extraction in acidulated water and drying using a spray dryer. The anthocyanin retention, antioxidant activity, water activity, solubility, color and microstructure of the final product were analyzed. Results showed that increase in the temperature did not cause significant changes in the anthocyanin quantity and antioxidant activity. The microscopic analysis revealed that for both the encapsulating agents, the absence of fissures and porosity in the particle surfaces produced powder with high solubility in water. The principal component analyses showed a strong correlation between the anthocyanin content and the antioxidant activity $(r=0.82)$ and luminosity $(r=0.81)$.
\end{abstract}

Key words: spray drying, red cabbage, anthocyanins, gum arabic, polydextrose

\section{INTRODUCTION}

Red cabbage is a vegetable that belongs to the Brassicaceae family and is native from the Mediterranean region and from the southwest of Europe, although it grows in various regions in the world (Arapitsas and Turner 2008). Studies related to the influence of the red cabbage in the human health have shown its activity in the prevention of heart diseases as well as its effects against some types of cancer (Dyrby et al. 2001; Wu et al. 2004; Charron et al. 2007). Among the substances present in the red cabbage responsible for these properties are the glucosinolates (van Poppel et al. 1999), polyphenols (Cooke et al. 2005; Singh et al. 2006; Charron et al. 2007), and anthocyanins, the class of phenolic compounds in highest abundance (Dyrby et al. 2001; Wu et al.
2004; Wu and Prior 2005; Charron et al. 2007). The anthocyanins pigments of the red cabbage comprise mainly of cyanidin 3-sophoroside-5glucoside and cyanidin 3-sophoroside-5-glucoside acylated with sinapic acid, ferulic acid, pcoumaric acid and malonic acid (Tanchev and Timberlake 1969; Hrazdina et al. 1977). The flavonoids, including acylated anthocyanins, found in the red cabbage, can act in vitro as scavengers of reactive oxygen species and electrophiles, and as chelators of metal ions (Radziejewska-Kubzdela and Bieganska-Marecik 2015).

Many studies revealed that anthocyanin stability is not only a consequence of the temperature, but also of structure, concentration, $\mathrm{pH}$, light, presence of co-pigments, free association, metallic ions, enzymes, oxygen, ascorbic acid, sugar and

*Author for correspondence: czapatan@ufrgs.br 
its degradation products, proteins and sulfur dioxide (Francis 1992; Rodriguez-Saona et al. 1999). Red cabbage contains glucoraphanin and glucobrassicin, which are precursors of sulforaphane and indole-3-carbinole, and may inhibit cancerogenesis at different stages of its development (Radziejewska-Kubzdela and Bieganska-Marecik 2015).

Several studies have reported the use of cabbage, such as the production of dietary fiber power from white cabbage outer leaves obtained by vacuum drying, which contains higher amounts of antioxidants and antioxidant activity (Tanongkankit et al. 2015), production of beverages based on apple juice with an addition of red cabbage added in the freeze-dried form (Radziejewska-Kubzdela and Bieganska-Marecik 2015), and the effect of temperature during drying in order to maximize the formation and minimize the degradation of sulforaphane compounds (Lekcharoenkul et al. 2014).

The gum Arabic is a soluble fiber containing nutritional properties that brings great health benefits due to its prebiotic effect, its high digestive tolerance and its beneficial impact on the glycemic impact of the final product. It has low caloric value and is considered appropriate for various formulations of functional food because it is not cariogenic (Badreldin et al. 2009). In addition, the gum Arabic is considered as one of the best encapsulating material.

The polydextrose is also a highly soluble dietary fiber, with high hygroscopicity, resistant to high temperature and well-tolerated by the human digestive system (Rosenthal 1995). It is extremely stable and colorless, does not leave residual taste and is also highly stable within a wide range of $\mathrm{pH}$ and temperature (Jie et al. 2000). One of its greatest advantages is its low caloric value in comparison to other carbohydrates $(1 \mathrm{kcal} / \mathrm{g})$. Besides that, it offers physiological benefits common to soluble dietary fibers, such as the production of short chain fatty acids, reduction of bowel transit time, decrease in the production of carcinogenic substances as well as the maintenance of the intestinal flora (Pronczuk and Hayes 2006; Gomes et al. 2007). It can be considered a prebiotic because it stimulates the growth of Lactobacillus and Bifidobacterium, and its fermentation continues along the colon, promoting the reduction of feces $\mathrm{pH}$ and the production of short chain fatty acids like the butyrate, which can reduce the risk of cancer (Jie et al. 2000).

This study aimed at studying the encapsulation of the red cabbage extract, through atomization drying, using gum Arabic and polydextrose as encapsulating materials. The influence of the encapsulating material and drying temperature on the moisture, water activity, anthocyanin retention, antioxidant activity, microstructure, color and powder solubility was evaluated.

\section{MATERIAL AND METHODS}

\section{Raw Material}

The red cabbage was purchased from the Central Supply of Rio Grande do Sul (CEASA) in Porto Alegre. The cabbage heads were selected considering the absence of visible injuries and infections, and then washed, dried and stored in perforated polyethylene bags at $7 \pm 2{ }^{\circ} \mathrm{C}$ until the time of processing.

\section{Experimental Procedure}

The red cabbage was shredded in slides of approximately $0.5 \mathrm{~cm}$ of thickness and subjected to steam blanching for $4 \mathrm{~min}$ followed by an ice bath. The anthocyanin extraction followed the method described by Chandrasekhar et al. (2012), with some modifications. Five hundred grams of blanched cabbage were macerated in $1000 \mathrm{~mL}$ acidified water containing citric acid at $2 \%(\mathrm{w} / \mathrm{v})$ for $16 \mathrm{~h}$ under the absence of light. After that, the extract was vacuum filtered using Whatman $\mathrm{n}^{\circ} 01$ filter paper and the extract was kept protected from light and immediately used for powder production.

For the microencapsulation, gum Arabic and polydextrose were added to the extract (10 and $15 \%$, w/v, respectively). Then the mixture was agitated with a homogenizer (Ultra Turrax IKA T25, Alemanha) at $4000 \mathrm{~g}$ for $5 \mathrm{~min}$ (Saénz et al. 2009). After that, the dispersion was atomized in double fluid spray dryer (MDS 1.0, Labmaq, Ribeirão Preto, Brazil), with a $1.0 \mathrm{~mm}$ feed nozzle at the air temperature of 140 and $160^{\circ} \mathrm{C}$. The powder collected was conditioned in envelopes of aluminum foil in plastic bags, which were sealed and kept in a dessicator containing silica.

\section{Anthocyanins Content}

The quantification of anthocyanins in the extract and in the atomized powders was performed using the spectrophotometric $\mathrm{pH}$ differential method as 
described by $\mathrm{Xu}$ et al. (2010). For each sample, solutions of potassium chloride $(0.025 \mathrm{M})$ and sodium acetate $(0.4 \mathrm{M})$ were prepared and adjusted to $\mathrm{pH} 1.0$ and 4.5 with hydrochloric acid, respectively. The absorbance of each solution was measured at 530 and $700 \mathrm{~nm}$ in UV-Visible spectrophotometer against a blank of distilled water. The anthocyanins content was calculated using Equation 1:

$$
\text { anthocyanins content }=\frac{A \cdot M w \cdot D F \cdot 1000}{\varepsilon \cdot L}
$$

Where: $A=\left[A_{530}\left(p H_{1.0}\right)-A_{700}\left(p H_{1.0}\right)\right]$ $\left[A_{530}\left(p H_{4.5}\right)-A_{700}\left(p H_{4.5}\right)\right] ; M w$ is the molecular weight of the anthocyanin $(433.2 \mathrm{~g} / \mathrm{mol}) ; D F$ is the dilution factor; $\varepsilon$ is the extinction coefficient $(31,600 \mathrm{~L} / \mathrm{cm} . \mathrm{mol})$ and $L$ is the optical path length $(1 \mathrm{~cm})$.

\section{Antioxidant Activity}

The antioxidant activity of the powders and of the extract was determined by the DPPH radical method of Brand-Williams et al. (1995) with a few changes. One milliliter of the extract was added to $4.0 \mathrm{~mL}$ methanol $50 \%$, and $0.2 \mathrm{~g}$ of powder was added to $6.4 \mathrm{~mL}$ of methanol $(50 \%)$. The mixture was left in the dark for $1 \mathrm{~h}$, exposed to the environment temperature. After that, the resulting extracts were vacuum filtered. Then, 0.1 $\mathrm{mL}$ of the extract was added to $3.9 \mathrm{~mL}$ of the solution of $0.06 \mathrm{mM}$ DPPH and left reacting in the dark at the environment temperature until reaching equilibrium. A control sample was prepared using $0.1 \mathrm{~mL}$ of a solution containing $10 \mathrm{~mL}$ of acidulated water $2 \%(\mathrm{~m} / \mathrm{v})$ and $40 \mathrm{~mL}$ of methanol $50 \%(\mathrm{v} / \mathrm{v})$. The readings were done at $515 \mathrm{~nm}$, against a white of pure methanol. The percentage of antioxidant activity was calculated by Equation 2:

$$
\% \text { antioxidant activity }=\left[1-\frac{A_{\text {sample }}}{A_{\text {control }}}\right] \times 100
$$

where $A_{\text {sample }}$ e $A_{\text {control }}$ represent the absorbance of the sample and the control, respectively.

\section{Color Measurement}

Color was measured by direct reading in a Minolta colorimeter (CR400/410, Minolta Sensing Inc., Osaka, Japan) through the three-dimensional system CIE $L * a * b *$. The instrument was standardized with a white ceramic plate $\left(L^{*}=97.47 ; a^{*}=0.08 ; b^{*}=1.76\right)$. The parameters
$L^{*} a^{*} b^{*}$ were used to calculate Chroma and browning index (BI) (Palou et al. 1999).

\section{Water Activity and Solubility}

The experimental values for water activity of the powders were obtained by direct reading in an electronic measuring apparatus (Aqualab 3TE, Decagon, Pullmann, USA) according to AOAC method no. 978.18 (1990). In order to determine the solubility of the powders atomized in water at $25^{\circ} \mathrm{C}$, the method of Eastman and Moore (1984) cited by Cano-Chauca et al. (2005) was used. One gram of powder was mixed in $100 \mathrm{~mL}$ of water and agitated in a magnetic stirrer (IKA lab disc, IKA® Werke Staufen, Germany) for $30 \mathrm{~min}$. Afterwards, an aliquot of $30 \mathrm{~mL}$ of the solution was centrifuged (Centrifuge, Sigma 4K15, Germany) at $2600 \mathrm{rpm}$ for $5 \mathrm{~min}$, and $10 \mathrm{~mL}$ of the supernatant were evaporated in an oven at $105^{\circ} \mathrm{C}$ for $20 \mathrm{~h}$. The solubility percentage was calculated using the difference in the weight of the powder before and after its drying in the oven.

\section{Microscopic analysis}

The microstructure of the powder samples was observed via scanning electron microscopy using the method recommended by Tonelli et al. (2008). This method consisted in adhering approximately one gram of sample to a double-sided tape in metallic supports (stubs) and covering the sample with a thin metal layer (SCD050, Bal-Tec, New York, USA). The samples were observed with the use of a scanning electron microscope (MEV) (JSM 6060, Jeol, Tokio, Japan) operating at a tension of $5 \mathrm{kV}$.

\section{Statistical Analysis}

The statistical analysis was done through the ANOVA variance analysis and the Tukey test was used for mean comparison among the treatments. The similarities and dissimilarities among the color parameters, content of anthocyanin, antioxidant activity, moisture, water activity and solubility were studied through the principal components analysis (PCA). For data analysis, the statistical software SAS 9.3 was used. The analyses were done in triplicate.

\section{RESULTS AND DISCUSSION}

\section{Anthocyanins retention}

The concentration of anthocyanin resulting of the extraction with acidified water was $261.02 \pm$ 
$14.48 \mathrm{mg} / 100 \mathrm{~g}$ of dry matter. Bronnum-Hansen et al. (1985) found that the addition of acid to the extraction means had a great effect on the stability of the anthocyanin, and increased the extraction efficiency. Park et al. (2014) found approximately 23 anthocycanins, among which the major anthocycanins were cyanidin-3-diglucoside-5glucoside derivatives with various acylated groups. In the atomized powders, this concentration varied between 193.82 and 251.13 $\mathrm{mg} / 100 \mathrm{~g}$ of dry matter. Although the drying process using spray dryer exposed the product to a high temperature for a short time, resulting in a reduced loss of thermosensitive compounds, the exit temperature of the product was an important factor to be considered regarding the retention of these compounds (Tonon et al. 2009).

Several works have reported loss of anthocyanin in red cabbage. Xu et al. (2014) studied the effect different cooking treatments, such as steaming, microwave heating, boiling and stir-frying on the nutritional quality of red cabbage. They found that all cooking methods caused significant reduction in anthocyanin and total glucosinolates contents. Radziejewska-Kubzdela and Bieganska-Marecik (2015) also observed decrease in the contents of phenolic acids and anthocyanins after thermal

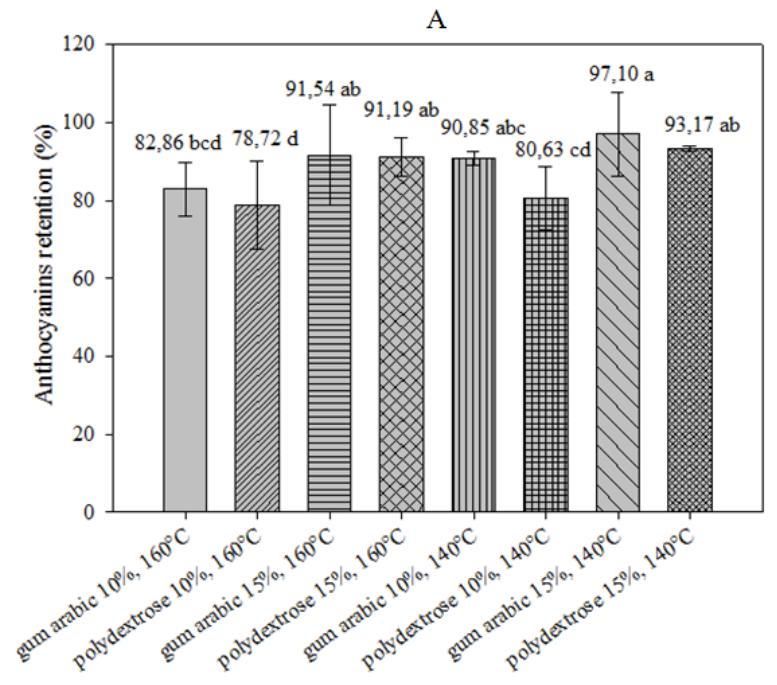

treatment in beverages produced with an addition of red cabbage freeze-dried form. Anthocyanins are very unstable to the factors such as temperature, light, $\mathrm{pH}$ and oxygen, and the objective of the encapsulation is to protect the core material from these adverse factors through the correct choice of the barrier material, which needs to be compatible with the food, have mechanical resistance, promote the appropriate dissolution and produce the desired particle size. The drying by spray dryer leads to the formation of a matrix system in which the polymer forms a tridimensional network around the encapsulated material in order to protect it from adverse factors (Tonon et al. 2010).

Figure 1 showed that higher retentions were obtained when $15 \%$ of the encapsulating agent was used. The values were higher for gum Arabic and had no significant difference $(\mathrm{p}>0.01)$ for polydextrose. Also, the powder with $10 \%$ of gum Arabic at $140^{\circ} \mathrm{C}$ presented high retention, with no significant difference for the powders with $15 \%$ of the same gum. It was possible to notice that, at a constant concentration, a temperature increase had no significant effect in the content of anthocyanin, indicating that the encapsulating agents were efficient in protecting these compounds.

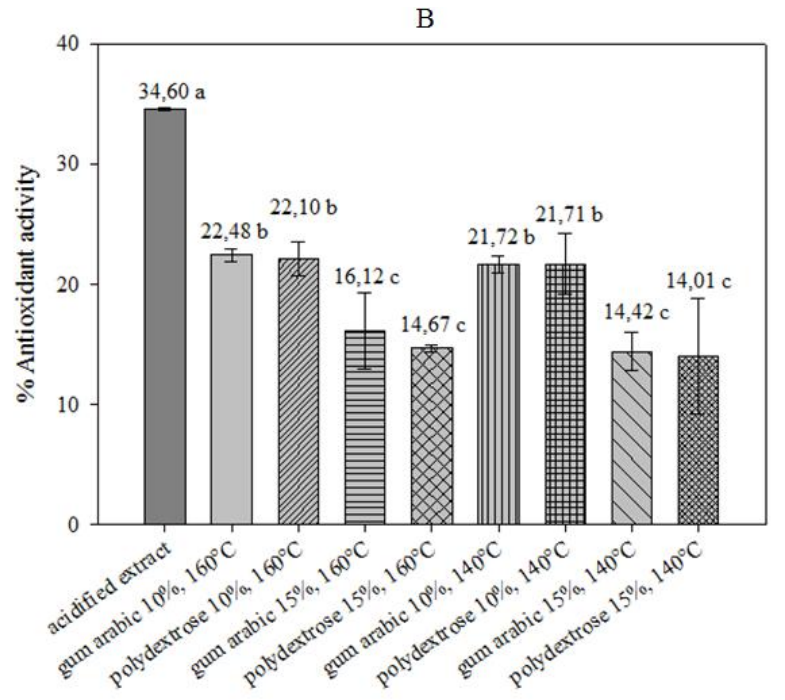

Figure 1 - Percentage of anthocyanins retention, in relation to the extract (A), and percentage of antioxidant activity (B) for the different treatments used.

\section{Antioxidant activity}

Several polyphenol compounds might have antioxidant activity. Gonzales et al. (2015) identified in red cabbage metabolites belonging to various classes, such as phenolic acid derivatives, flavonoid glycosides, acylated flavonoid glycosides, glucosinolates and anthocyanins. The antioxidant activity of the extract in acidified 
water was approximately $34.6 \%$ and, in dehydrated products, it decreased to a level between 14 and 22.5\%. According to JiménezAguilar et al. (2011), this decrease was a consequence of high air temperatures in the atomizer exit, which provoked a degradation of the compounds responsible for the antioxidant activity. Tanongkankit et al. (2015) found that the total antioxidant activity, as measured by the DPPH radical scavenging, continuously decreased during the drying. Xu et al. (2014) also reported that the DPPH radical-scavenging activity was affected by the cooking methods in red cabbage. Figure 1 also showed that the antioxidant activity was significantly higher $(\mathrm{p}<0.01)$ with $10 \%$ of the encapsulant than with $15 \%$. This could be explained by the increase of dry matter caused by the increment in the encapsulating agent quantity. With the rise in temperature, there was no significant difference $(p>0.01)$ in the antioxidant activity, indicating that the encapsulating agents were efficient in protecting the anthocyanin, the main components responsible for the antioxidant activity, keeping them stable with the rise in temperature in the level studied.

\section{Water activity and solubility}

The lowest values in water activity occurred with the use of gum Arabic. However, all the powders presented water activity below 0.2, which indicated that they all had high stability. It was also found that all powders were highly water soluble, with solubility values above $98.85 \%$. Gum Arabic was slightly more soluble than polydextrose. The lowest solubility was obtained with polydextrose at $15 \%$ and $140^{\circ} \mathrm{C}$. In a study with açai juice, Tonon et al. (2009) used gum Arabic as a wall material in the drying, by atomization results in highly soluble products and reported solubility values higher than $94 \%$.

\section{Color changes}

Table 1 showed that the lowest value of $L^{*}$ was obtained with polydextrose at $10 \%$ and at $160^{\circ} \mathrm{C}$ $(\mathrm{p}<0.01)$. With this encapsulating agent and with gum Arabic at $15 \%$, as well as with the rise in temperature, the value of $L^{*}$ decreased significantly $(\mathrm{p}<0.01)$. This decrease resulted in darker products due to the influence of Maillard reactions (Veja-Gálvez et al. 2009). The increase in encapsulating agent concentration caused $L^{*}$ to increase, because both wall materials presented a white color $\left(L^{*}=92.46-\right.$ gum Arabic; $L^{*}=93.69$ - polydextrose), and thus, diluted the typical purple color of the red cabbage (Quek et al. 2007). In general, the values of $a^{*}$ and $b^{*}$ decreased significantly $(\mathrm{p}<0.01)$ with a higher concentration of the encapsulating material, provoking a reduction in the yellow and green tonalities, also associated to the addition of the encapsulating agents. Chroma presented the same behavior, since it was directly proportional to the parameters $a^{*}$ and $b^{*}$. The browning index $(B I)$ increased significantly $(\mathrm{p}<0.01)$ with the temperature increase, and fell with the increase of encapsulating agent concentration. The increase of $B I$ with the temperature rise could be due both to thermal degradation of anthocyanins and the Maillard reactions caused by the heat.

Table 1 - Color parameters of the red cabbage powder obtained for spray drying at 140 and $160^{\circ} \mathrm{C}$ and with concentrations of gum arabic and polydextrose of 10 and $15 \%$.

\begin{tabular}{|c|c|c|c|c|c|}
\hline & $L^{*}$ & $a^{*}$ & $b^{*}$ & Chroma & $B I$ \\
\hline \multicolumn{6}{|l|}{ Gum Arabic } \\
\hline $10 \%, 140^{\circ} \mathrm{C}$ & $72.37 \pm 0.330^{\mathrm{cd}}$ & $36.54 \pm 0.273^{d}$ & $-4.26 \pm 0.047^{f}$ & $36.77 \pm 0.273^{\mathrm{d}}$ & $27.43 \pm 0.326^{f}$ \\
\hline $15 \%, 140^{\circ} \mathrm{C}$ & $75.79 \pm 0.093^{\mathrm{a}}$ & $30.13 \pm 0.080^{\mathrm{h}}$ & $-4.07 \pm 0.031^{\mathrm{e}}$ & $30.54 \pm 0.081^{\mathrm{h}}$ & $20.09 \pm 0.076^{\mathrm{h}}$ \\
\hline $10 \%, 160^{\circ} \mathrm{C}$ & $71.85 \pm 0.253^{\mathrm{cd}}$ & $34.96 \pm 0.106^{f}$ & $-2.43 \pm 0.097^{\mathrm{d}}$ & $35.04 \pm 0.105^{f}$ & $28.71 \pm 0.258^{\mathrm{e}}$ \\
\hline $15 \%, 160^{\circ} \mathrm{C}$ & $74.06 \pm 0.305^{\mathrm{b}}$ & $31.47 \pm 0.359^{g}$ & $-4.60 \pm 0.025^{\mathrm{g}}$ & $31.81 \pm 0.356^{\mathrm{g}}$ & $22.11 \pm 0.337^{\mathrm{g}}$ \\
\hline \multicolumn{6}{|l|}{ Polydextrose } \\
\hline $10 \%, 140^{\circ} \mathrm{C}$ & $71.46 \pm 0.251^{\mathrm{d}}$ & $39.33 \pm 0.220^{b}$ & $-0.52 \pm 0.069^{c}$ & $39.34 \pm 0.219^{b}$ & $35.29 \pm 0.382^{b}$ \\
\hline $15 \%, 140^{\circ} \mathrm{C}$ & $73.32 \pm 0.110^{\mathrm{bc}}$ & $35.64 \pm 0.186^{\mathrm{e}}$ & $-0.68 \pm 0.044^{c}$ & $35.65 \pm 0.185^{\mathrm{e}}$ & $31.21 \pm 0.249^{d}$ \\
\hline $10 \%, 160^{\circ} \mathrm{C}$ & $64.58 \pm 0.072^{\mathrm{e}}$ & $43.19 \pm 0.079^{\mathrm{a}}$ & $3.85 \pm 0.168^{\mathrm{a}}$ & $43.36 \pm 0.065^{\mathrm{a}}$ & $49.59 \pm 0.268^{a}$ \\
\hline $15 \%, 160^{\circ} \mathrm{C}$ & $71.72 \pm 0.352^{\mathrm{d}}$ & $37.48 \pm 0.100^{c}$ & $0.08 \pm 0.085^{\mathrm{b}}$ & $37.48 \pm 0.100^{c}$ & $34.51 \pm 0.288^{c}$ \\
\hline
\end{tabular}

Values expressed as the mean \pm standard deviation.

The same small letters in the same column indicate no significant difference. 


\section{Microscopic analysis}

In Figure 2, the visible difference of shapes and sizes of atomized microcapsules can be observed, as well as the differences in structure of both encapsulating agents. In the powders with gum Arabic, there were globular capsules with rough surfaces. This effect was probably due to the cooling after the swelling with the water vapor exit. Various studies have shown that the particles from gum Arabic were spherical in shape and contained many concavities (Krishnan et al. 2005; Fernandes et al. 2012). According to RodríguezHuezo et al. (2007), these surface concavities generate features like resistance to mechanical fractures and to diffusion in the resulting powders. The formation of concavities in the powders atomized with gum Arabic may be a result of the particle shrinking that takes places due to the rapid evaporation during the drying process (Osorio et al. 2010).
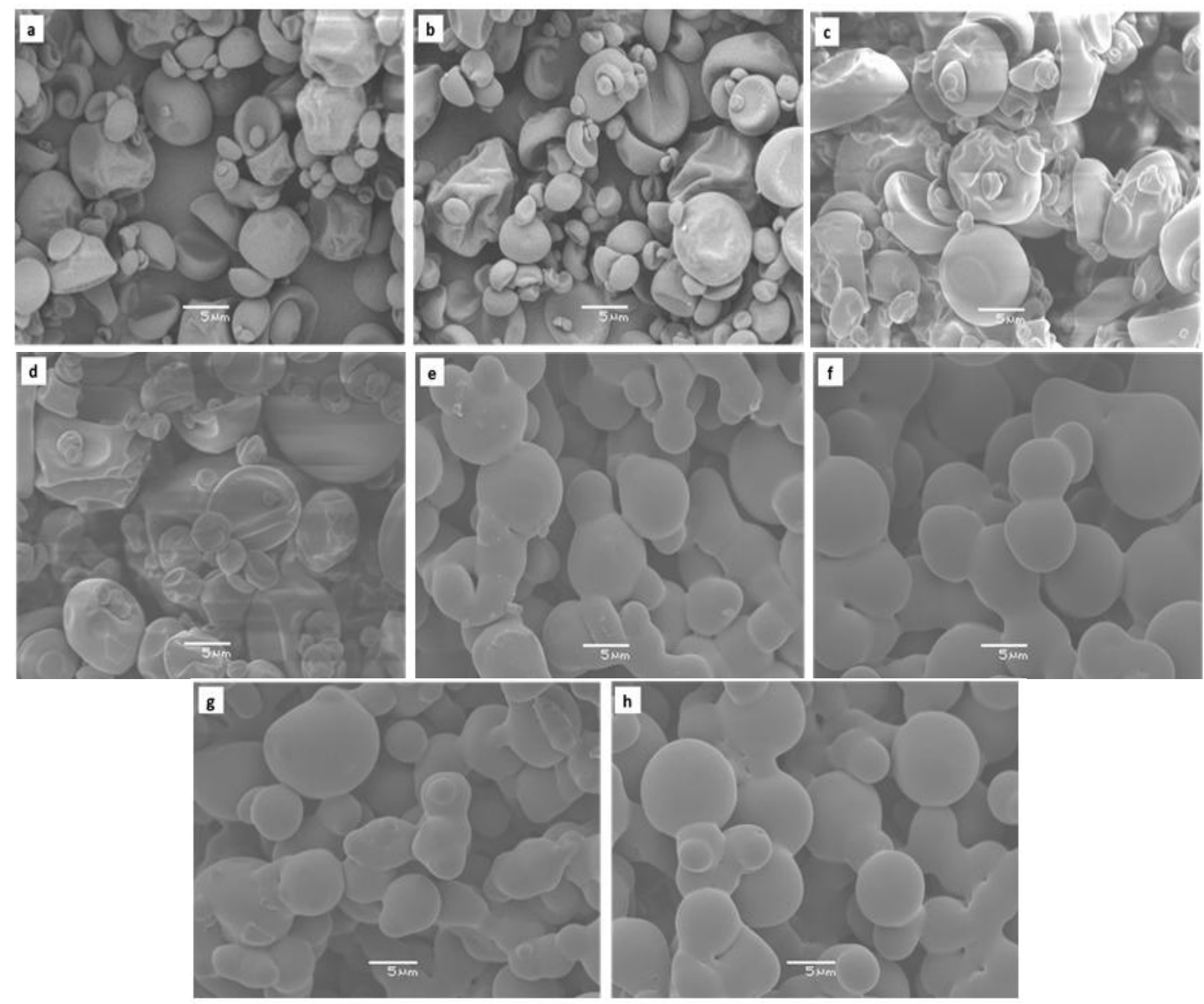

Figure 2 - Electron microscopy image of the red cabbage extract atomized with $10 \%$ of gum arabic at $140^{\circ} \mathrm{C}(\mathrm{a}), 160^{\circ} \mathrm{C}(\mathrm{b}) ; 15 \%$ of gum arabic at $140^{\circ} \mathrm{C}(\mathrm{c}), 160^{\circ} \mathrm{C}(\mathrm{d}) ; 10 \%$ of polydextrose at $140^{\circ} \mathrm{C}(\mathrm{e}), 160^{\circ} \mathrm{C}(\mathrm{f}) ; 15 \%$ of polydextrose at $140^{\circ} \mathrm{C}(\mathrm{g}), 160^{\circ} \mathrm{C}(\mathrm{h})$. Magnification of $3,000 \times$.

When using gum Arabic, it was also possible to observe the adhesion of smaller particles to the bigger ones, similarly to what was observed by Cano-Chauca et al. (2005) for the mango juice atomized with gum Arabic. In the microstructure of the powders with polydextrose, the particles were bigger and had a globular shape with a spherical tendency, pilled one over another and showed strong attraction to each other. According to Fazaeli et al. (2012), this was probably due to 
the encapsulating material molecular structure, which was a polymer of glucose molecules united by $\alpha-1,6$ connections, containing sorbitol and/or monoester linkages of citric acid as their terminal group (Gomes et al. 2007). The external surface of the particles presented a continuing wall with no fissures, cracks, or interruptions, an essential factor to ensure a lower air permeability and better product protection (Silva et al. 2013).

\section{Multivariate analysis}

The results obtained in PCA (Fig. 3) showed that the variables could be reduced to two main components, which accounted for $89.69 \%$ of the total variability of the results. The first main component (PC1) represented $72.27 \%$ of the total variability, while the second one (PC2) was responsible for $17.42 \%$ of the data variation. These results confirmed that the two main components were highly significant for the classification of the features of the atomized powders.

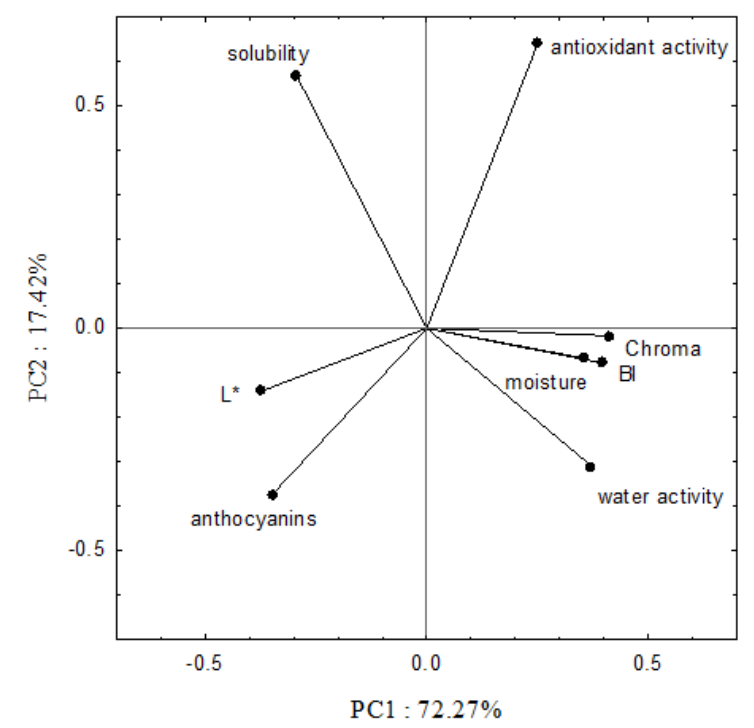

Figure 3 - Principal component analysis for the powders with red cabbage extract.

PC1 was strongly correlated to anthocyanins content $(\mathrm{r}=0.84)$, water activity $(\mathrm{r}=0.89), L^{*}(\mathrm{r}=$ 0.89), $B I(\mathrm{r}=0.96)$ and Chroma $(\mathrm{r}=0.99)$ (Fig. 3), where, according to Kilimann et al. (2006), the measures that were more distant from zero and the smaller angles between the main component and the variables corresponded to the strong association that existed among them. PC2 showed a correlation with solubility $(r=0.70)$ and antioxidant activity $(r=0.76)$.
Figure 3 also showed the strong correlation between the anthocyanins content with luminosity $(\mathrm{r}=0.81)$ and with antioxidant activity $(\mathrm{r}=0.82)$, because as seen before, purple color of the extract and, consequently, of the powders was related to the anthocyanins content: the higher this content, the darker the powder and the lower its luminosity. Besides, the anthocyanins are the main compounds responsible for the antioxidant activity of the product studied. Tanongkankit et al. (2015) found high correlation coefficient between the total phenolic compounds and total antioxidant activity after drying of cabbage dietary fiber, indicating that these compounds played an important role on the antioxidant activity. Radziejewska-Kubzdela and Bieganska-Marecik (2015) also found a strong correlation between the antioxidant capacity and hydroxycinnamic acids, flavonoids and total contents of phenolics after thermal heating of beverages of apple juice with red cabbage.

\section{CONCLUSION}

It was concluded that the increase in the temperature from 140 to $160^{\circ} \mathrm{C}$ did not provoke significant changes in the anthocyanin and antioxidant activity contents. This indicated that the encapsulating agents protected these compounds efficiently. All the powders presented water activity below 0.2 , which indicated they were highly stable products. Both the encapsulating agents produced powder with high water solubility (higher than 98.85\%), and gum Arabic was slightly more soluble than polydextrose. The powder that presented the highest anthocyanin retention was the one produced with $15 \%$ of gum Arabic at $140^{\circ} \mathrm{C}$. The microscopic analysis revealed that for both the encapsulating agents, the absence of fissures and porosity in the particle surfaces, which might indicate a complete coverage of the encapsulating material. The principal components analysis revealed a strong correlation between the anthocyanins content and antioxidant activity and luminosity.

\section{ACKNOWLEDGEMENTS}

This work was supported by the Brazilian agencies CNPq, CAPES and FAPERGS. 


\section{REFERENCES}

AOAC, (1984) Official Methods of Analysis of the Association of Official Analytical Chemists. Washington, DC.

AOAC, (1990) Official Methods of Analysis of the Association of Official Analytical Chemists. Washington, DC.

Arapitsas P, Turner C. Pressurized solvent extraction and monolithic column-HPLC/DAD analysis of anthocyanins in red cabbage. Talanta. 2008; 74: 1218-1223.

Badreldin AH, Ziada A., Blunden G. Biological effects of gum arabic: A review of some recent research. Food Chem Toxicol. 2009; 47: 1-8.

Brand-Williams W, Cuvelier ME, Berset C. Use of a free radical method to evaluate antioxidant activity. LWT - Food Sci Technol. 1995; 28: 25-30.

Bronnum-Hansen K, Jacobsen F, Flink JM. Anthocyanin colourants from elderberry (Sambucus nigra L.). 1. Process considerations for production of the liquid extract. Int J Food Sci Technol. 1985; 20: 703-711.

Cano-Chauca M, Stringheta PC, Ramos AM, Cal-Vidal J. Effect of the carriers on the microstructure of mango powder obtained by spray drying and its functional characterization. Innovat Food Sci Emerg Tech. 2005; 6: 420-428.

Chandrasekhar J, Madhusudhan MC, Raghavarao KSMS. Extraction of anthocyanins from red cabbage and purification using adsorption. Food Bioprod Process. 2012; 90: 615-623.

Charron CS, Clevidence BA, Britz SJ, Novotny JA. Effect of dose size on bioavailability of acylated and nonacylated anthocyanins from Red Cabbage (Brassica oleracea L. Var. capitata). J Agric Food Chem. 2007; 55: 5354-5362.

Cooke D, Steward WP, Gescher AJ, Marczylo T. Anthocyanins from fruits and vegetables - Does bright colour signal cancer chemopreventive activity? Eur J Cancer. 2005; 41: 1931-1940.

Dyrby M, Westergaard N, Stapelfeldt H. Light and heat sensitivity of red cabbage extract in soft drink model systems. Food Chem. 2001; 72: 431-437.

Eastman JE, Moore CO. Cold water soluble granular starch for gelled food composition. 1984. U.S. Patent 4465702.

Fazaeli M, Emam-Djomeh Z, Ashtari AK, Omid M. Effect of spray drying conditions and feed composition on the physical properties of black mulberry juice powder. Food Bioprod Process. 2012; 90: 667-675.

Fernandes LP, Candido RC, Oliveira WP. Spray drying microencapsulation of Lippia sidoides extracts in carbohydrate blends. Food Bioprod Process. 2012; 90: 425-432.

Francis FJ. A new group of food colorants. Trends Food Sci Tech. 1992; 3: 27-30.
Gomes CR, Vissotto FZ, Fadini AL, Faria EV, Luiz AM. Influence of different bulk agents in the rheological and sensory characteristics of diet and light chocolate. Cienc Tecnol Aliment. 2007; 27: 614623.

Gonzales GB, Raes K, Vanhoutte K, Coelus S, Smagghe G, Camp JV. Liquid chromatography-mass spectrometry coupled with multivariate analysis for the characterization and discrimination of extractable and non extractable polyphenols and glucosinolates from red cabbage and Brussels sprout waste streams. J Chromatogr A. 2015; 1402: 60-70.

Hrazdina G, Iradale H, Mattick L. Anthocyanins composition of Brassica oleracea cv. Red Danish. Phytochem. 1977; 16: 297-299.

Jie Z, Bang-You L, Ming-Jie X, Hai-Wei L, Zu-Kang Z, Ting-Son W, et al. Studies on the effects on the polydextrose intake on physiologic functions on Chinese people. Am J Clin Nutr. 2000, 72, 1503-1509. Jiménez-Aguilar DM, Ortega-Regules AE, LozadaRamírez JD, Pérez-Pérez MCI, Vernon-Carter EJ, Welti-Chanes J. Color and chemical stability of spraydried blueberry extract using mesquite gum as wall material. J Food Compos Anal. 2011; 24: 889-894.

Kilimann KV, Hartmann C, Delgado A, Vogel RF, Ganzle MG. Combined high pressure and temperature induced lethal and sublethal injury of Lactococcus lactis - Application of multivariate statistical analysis. Int J Food Microbiol. 2006; 109: 25-33.

Krishnan S, Kshirsagar AC, Singhal RS. The use of gum arabic and modified starch in the microencapsulation of a food flavoring agent. Carbohydr Polym. 2005; 62: 309-315.

Lekcharoenkul P, Tanongkankit Y, Chiewchan N, Devahastin S. Enhancement of sulforaphane content in cabbage outer leaves using hybrid drying technique and stepwise change of drying temperature. J Food Eng. 2014; 122: 56-61.

Osorio C, Acevedo B, Hillebrand S, Carriazo J, Winterhalter P, Morales AL. Microencapsulation by spray-drying of anthocyanin pigments from corozo (Bactris guineensis) fruit. J Agric Food Chem. 2010; 58: 6977-6985.

Palou A, López-Malo A, Barbosa-Cánovas GV, WeltiChanes J, Swanson BG. Polyphenoloxidase activity and color of blanched and high hydrostatic pressure treated banana puree. J Food Sci. 1999; 64: 42-45.

Park S, Arasu MV, Jiang N, Choi SH, Lim YP, Park JT, et al. Metabolite profiling of phenolics, anthocyanins and flavonols in cabbage (Brassica oleracea var. capitata). Ind Crop Prod. 2014; 60: 8-14.

Pronczuk A, Hayes KC. Hypocholesterolemic effect of dietary polydextrose in gerbils and humans. Nutr Res. 2006; 26: 27-31.

Quek SY, Chok NK, Swedlund P. The physicochemical properties of spray-dried watermelon powders. Chem Eng Process. 2007; 46: 386-392. 
Radziejewska-Kubzdela E, Bieganska-Marecik R. A comparison of the composition and antioxidant capacity of novel beverages with an addition of red cabbage in the frozen, puree and freeze-dried forms. LWT - Food Sci Technol. 2015; 62: 821-829.

Rodríguez-Huezo ME, Durán-Lugo R, Prado-Barragán LA, Cruz-Sosa F, Lobato-Calleros C, AlvarezRamírez J, et al. Pre-selection of protective colloids for enhanced viability of Bifidobacterium bifidum following spray-drying and storage, and evaluation of aguamiel as thermoprotective prebiotic. Food Res Int. 2007; 40: 1299-1306.

Rodriguez-Saona LE, Giusti MM, Wrolstad RE. Color and pigment stability of red radish and red-fleshed potato anthocyanins in juice model systems. J Food Sci. 1999; 64: 451-456.

Rosenthal AJ. Application of aged egg in enabling increased substitution of sucrose by litesse (polydextrose) in high-ratio cakes. J Sci Food Agr. 1995; 68: 127-131.

Saénz C, Tapia S, Chávez J, Robert P. Microencapsulation by spray drying of bioactive compounds from cactos pear (Opuntia fícus-indica). Food Chem. 2009; 114: 616-622.

Silva FC, Fonseca CR, Alencar SM, Thomazini M, Balieiro JC, Pittia P, Favaro-Trindade CS. Assessment of production efficiency, physicochemical properties and storage stability of spray-dried própolis, a natural food additive, using gum Arabic and OSA strach-based carrier systems. Food Bioprod Process. 2013; 91: 28-36.

Singh J, Upadhyay AK, Bahadur A. Singh B, Singh KP, Rai M. Antioxidant phytochemicals in cabbage (Brassica oleracea L. var. capitata). Sci Hort. 2006; 108: 233-237.

Tanchev SS, Timberlake CF. The anthocyanins of red cabbage (Brassica oleracea). Phytochem. 1969; 8: 1825-1827.

Tanongkankit Y, Chiewchan N, Devahastin S. Evolution of antioxidants in dietary fiber powder produced from white cabbage outer leaves: effects of blanching and drying methods. J Food Sci Technol. 2015; 52: 2280-2287.
Tonelli J, Park K, Murr FEX, Negreiros AA. Effect of moisture on the microstructure of inulin powder. Food Sci Technol. 2008; 28: 122-131.

Tonon RV, Brabet C, Hubinger MD. Anthocyanin stability and antioxidant activity of spray-dried açai (Euterpe oleracea Mart.) juice produced with different carrier agents. Food Res Int. 2010; 43: 907914.

Tonon RV, Brabet C, Pallet D, Brat P, Hubinger M. Physicochemical and morphological characterization of açai (Euterpe oleraceae Mart.) powder produced with different carrier agents. Int J Food Sci Technol. 2009; 44: 1950-1958.

Van Poppel G, Verhoeven DTH, Verhagen H, Goldbohm RA. Brassica vegetables and cancer prevention - Epidemiology and mechanisms. Adv Exp Med. 1999; 472: 159-168.

Veja-Gálvez A, Di Scala K, Rodríguez K, LemusMondaca R, Miranda M, López J, Perez-Won M. Effect of air-drying temperature on physico-chemical properties, antioxidant capacity, colour and total phenolic content of red pepper (Capsicum annuum, L. var. Hungarian). Food Chem. 2009; 117: 647-653.

Wu X, Beecher GR, Holden JM, Haytowitz DB, Gebhardt SE, Prior RL. Lipophilic and hydrophilic antioxidant capacities of common foods in the United States. J Agric Food Chem. 2004; 52: 4026-4037.

$\mathrm{Wu} \mathrm{X}$, Prior RL. Identification and characterization of anthocyanins by high-performance liquid chromatography-electrospray ionization-tandem mass spectrometry in common foods in the United States: Vegetables, nuts, and grains. J Agric Food Chem. 2005; 53: 3101-3113.

$\mathrm{Xu} \mathrm{F}$, Zheng Y, Yang Z, Cao S, Shao X, Wang H. Domestic cooking methods affect the nutritional quality of red cabbage. Food Chem. 2014; 161: 162167.

$\mathrm{Xu} \mathrm{Z,} \mathrm{Wu} \mathrm{J,} \mathrm{Zhang} \mathrm{Y,} \mathrm{Hu} \mathrm{X,} \mathrm{Liao} \mathrm{X,} \mathrm{Wang} \mathrm{Z.}$ Extraction of anthocyanins from red cabbage using high pressure $\mathrm{CO}_{2}$. Bioresource Technol. 2010; 101: 7151-7157. 